\title{
Infection, immunosuppression, and treatment of auto-immune inflammatory kidney disease
}

\author{
Diana Póvoas ${ }^{1}$ \\ ${ }^{1}$ Infectious Diseases Unit, Hospital de Curry Cabral, Centro Hospitalar Universitário Lisboa Central, EPE, Lisbon, Portugal
}

\section{ABSTRACT}

Immunosuppressive drugs are the cornerstone of treatment of auto-immune inflammatory diseases (AlIDs) with renal involvement. However, the most commonly used drugs in this setting can increase the risk of bacterial, fungal, and viral infection, and also impair immune response following vaccination. Recommendations and evidence on strategies for infection prevention in the setting of AlIDs treatment will be reviewed.

Key-words: immunosuppression, infection, prevention

C 2021 Portuguese Journal of Nephrology \& Hypertension. Published by Publicações Ciência \& Vida This is an open access article under the CC BY-NC-ND license (http://creativecommons.org/licenses/by-nc-nd/4.0/).

\section{INTRODUCTION}

Immunosuppressive drugs play a major role in the treatment of immune-mediated inflammatory renal diseases, as well as in renal transplantation. In the setting of auto-immune inflammatory diseases (AlIDs), infection risk is determined not only by immunosuppressive drugs, but also by physiological mechanisms such as edema, immune cell dysregulation, and urinary loss of immunoglobulins (Ig) and complement components ${ }^{1}$.

Immunosuppression benefits, inflammatory disease control, and risk of infection are intimately related: immunosuppressants increase infection risk, infection treatment requires immunosuppressive therapy adjustment that could increase inflammatory activity, but infection may also be a trigger for some diseases to relapse ${ }^{2}$.

Since infection is a major cause of morbidity and treatment interference, infection risk assessment and individualized preventive strategies are important.

\section{KIDNEY DISEASE, IMMUNOSUPPRESSIVE DRUGS, AND INFECTION RISK}

Patients with kidney disease requiring treatment with immunosuppression are at a higher risk of infection. A cohort study of 489 patients with anti-neutrophil cytoplasmic antibody (ANCA) associated vasculitis (AAV) treated with immunosuppression showed a cumulative incidence of infection at 1,2 , and 5 years of 51,58 , and $65 \%$, respectively, and of severe infection of 22,23 , and $26 \%^{2}$. Another recent study of 379 AAV patients showed these patients are seven times more likely to have laboratory-confirmed infections, and four times more likely to develop infections requiring hospitalization ${ }^{3}$. The underlying AIID also impacts infection risk, as observed in a study comparing 872 patients with AAV and systemic lupus erythematosus (SLE), with the former showing a higher risk of hospitalization due to infection, as well as poorer outcome of infection episodes while on immunosuppressive therapy ${ }^{4}$.

Commonly used drugs for glomerulonephritis treatment include corticosteroids, cyclophosphamide, rituximab, mycophenolate mofetil (MMF), and azathioprine. These drugs may be used separately, in combination regimens, or sequentially, depending on the diagnosis, clinical features, and in regard to induction or maintenance treatment stage. In some cases, plasma exchange may also be necessary.

Several studies have evaluated the risk of infection associated with different immunosuppressive regimens used to treat immune-mediated glomerulonephritis.

Methotrexate, along with belimumab and calcineurin inhibitors such as tacrolimus, may be used in AAV or lupus nephritis, but these drugs are usually not considered as first-line therapy, and therefore will not be analyzed in this review.

\section{CYCLOPHOSPHAMIDE}

The alkylating agent cyclophosphamide is one of the most immunosuppressive therapies available. During treatment, complete differential blood counts should be obtained regularly to screen for bone marrow toxicity. Cyclophosphamide should be avoided in 
neutropenic patients, unless neutropenia is perceived as being immune-mediated.

Higher cyclophosphamide doses and long treatment duration increase the risk of hematologic toxicity ${ }^{5}$. Leukopenia is common and granulocytes are likely to be affected within days to a few weeks of treatment. Lymphopenia may also occur, particularly if high doses of corticosteroids are also being used. In this setting of concomitant treatment with high-dose corticosteroids, a total white blood cell count below $4000 / \mathrm{mm}^{3}$ implies underlying immunosuppression, even if the absolute neutrophil count is above $1500 / \mathrm{mm}^{3}$, since high-dose corticosteroids cause polymorphonuclear cells to demarginate ${ }^{6}$. Prompt dose adjustments should be made in leucopenia or neutropenia. However, this may not be necessary in the presence of isolated lymphopenia, as long as patients are on Pneumocystis jirovecii pneumonia (PCP) prophylaxis, recommended for almost all patients on cyclophosphamide?.

\section{RITUXIMAB}

Rituximab is a CD20-targeting monoclonal chimeric antibody, causing depletion of $B$ cells. $B$ cell depletion is reversible after interruption of rituximab treatment, since stem cells and earlier $B$ cell precursors lack the CD20 antigen and can migrate from the bone marrow to secondary lymphoid tissue to reconstitute the B cell reservoir. Subsequent normalization of $B$ cells usually takes place six to nine months or longer after treatment interruption.

Although rituximab is mainly a B-cell depleting agent, data from rheumatoid arthritis (RA) patients suggest treatment may also significantly decrease the number of peripheral blood T cells, particularly $\mathrm{CD}^{+}$cells, months later after treatment initiation ${ }^{8}$. Additionally, experimental murine models also showed treatment with anti-CD20 drugs could also affect the development or establishment of $C D 8^{+} \mathrm{T}$ cell responses, which are necessary for the control of intracellular infections ${ }^{9}$. Clinical relevance of these findings requires further clarification.

Rituximab should be avoided in severely immunocompromised patients or when there is an active, severe infection.

B cell depletion may cause some degree of hypogammaglobulinemia, impairment on vaccine responses, as well as an increase in the risk of opportunistic infections or viral infection reactivation. Hence, prior to treatment, patients should be screened for hepatitis $B$ virus (HBV), hepatitis C virus and human immunodeficiency virus (HIV) infection. In HBV-negative, unvaccinated patients, immunization against $\mathrm{HBV}$ is advisable.

Assessment of baseline levels of serum immunoglobulins is also recommended, including IgM, IgG, and IgA. Additionally, some authors strongly advocate for flow cytometry and peripheral B cells quantification prior to treatment, as a risk-assessment tool of rituximab-induced hypogammaglobulinemia and infectious complications ${ }^{10}$. Despite the lack of surface CD20 in plasma cells, IgG, IgM, and, least frequently, IgA hypogammaglobulinemia may occur in rituximab-treated patients ${ }^{11}$, and repeated courses of rituximab, older age, and pre-existing hypogammaglobulinemia have been identified as possible risk factors ${ }^{10}$. Incidence appears to be lower in AAV, compared to cancer and RA patients ${ }^{10}$.

Infections can occur anytime during treatment, but seem to be more frequent during the first three months post-treatment. Infection risk may be related to hypogammaglobulinemia, impaired humoral response, as well as dysfunction in T-cell responses due to reduction in antigen-presenting cells in the setting of B cell depletion ${ }^{10}$.

Sinopulmonary infections are the most common infectious complications. HBV reactivation (HBV-R) risk must be assessed (see below). Higher rates of PCP have also been described, and, in the setting of AllDs treatment, particularly RA patients, and previously exposed to other immunosuppressive treatments, rare episodes of cryptococcal meningitis ${ }^{12,13}$, cytomegalovirus (CMV) colitis, Nocardiosis ${ }^{14}$, Echinococcus infection ${ }^{15}$ and progressive multifocal leukoencephalopathy ${ }^{16}$ (PML) have also been reported. Rituximab suspension is strongly recommended in cases of severe hypogammaglobulinemia, severe or recurrent infections, or if PML is suspected.

Late-onset neutropenia (LON) may also occur during rituximab treatment, and the underlying mechanism is still unknown. A recent retrospective cohort review of 738 rituximab-treated patients at a vasculitis and glomerulonephritis referral center found a cumulative incidence for LON of $6.6 \%$ at one year, a higher risk of LON in the first year of treatment, and severe infections potential; SLE and combination therapy with cyclophosphamide were found to be independent risk factors for LON development ${ }^{17}$.

\section{ANTIMETABOLITES: MYCOPHENOLATE MOFETIL AND AZATHIOPRINE}

MMF inhibits lymphocyte proliferation through the inhibition of inosine monophosphate dehydrogenase. It is commonly used for the prevention of organ transplant rejection, and as a corticosteroid-sparing agent in the treatment of a wide range of AlIDs. Infection risk is not thoroughly characterized in MMF-treated AAIDs patients, and most of the available data regards MMF use within solid-organ transplantation. In comparison to other immunosuppressive drugs used in the treatment of AAIDs, MMF is not usually considered to significantly increase the risk of opportunistic infections. However, a recent meta-analysis on the role of MMF in AAV patients found a similar rate of infection as the one observed in cyclophosphamide-treated patients ${ }^{18}$.

Azathioprine is a derivate of the purine-mimic antimetabolite thioguanine, and the prodrug of 6-mercaptopurine. Azathioprine and 6-mercaptopurine cause a reduction of circulating $B$ and T lymphocytes, reduce immunoglobulin synthesis, diminish interleukin-2 secretion, and inhibit the intracellular signaling of T-cell costimulation through CD28-mediated pathways ${ }^{19,20}$.

Even though infection is a common side effect of azathioprine, infection risk is still poorly characterized. Case series reports which stem from a wide range of AAIDs, including neurological, rheumatological, and gastrointestinal disorders, describe increased infection 
risk with simultaneous use of other immunosuppressive drugs, such as corticosteroids, or other immunomodulatory drugs ${ }^{21}$.

Overall, infectious complications reported with the use of antimetabolites include bacterial infections, such as Listeriosis and mycobacterial infections, but also fungal and viral infections such as Herpes zoster $^{6}(\mathrm{HZ})$. Antimetabolites use and PML risk is addressed below.

\section{TUBERCULOSIS}

Latent infection by Mycobacterium tuberculosis complex (Mtb) is a dynamic process and the outcome of Mtb infection represents a wide range of immune responses to infecting mycobacteria. At one end of the spectrum, there is the possibility of successful eliminating mycobacteria and at the opposite end, fierce bacterial replication may result in fulminant tuberculosis (TB) and sepsis ${ }^{22}$. The outcome of this process is influenced by the net amount of immunosuppression that results from a specific AIID and its underlying immune dysfunction and/or inflammatory disease activity, on top of which treatment with immunosuppressive drugs overlaps ${ }^{23}$. Even what may be considered as low-risk immunosuppressive treatment, such as low-dose corticosteroid use, can impair the immune responses triggered by exposure to mycobacteria, hence increasing the risk of active tuberculosis. This risk rises with increasing doses of corticosteroid therapy, but even with lower doses it is still not negligible, as indicated by an odds ratio close to 3 of progressing from latent to active TB when prednisone $<15 \mathrm{mg} /$ day is used ${ }^{24,25}$.

Unlike active TB, there still is no gold-standard method for the diagnosis of latent TB (LTB). National guidelines unanimously identify patients eligible for treatment of LTB as those who, after having active TB ruled out, have either a positive interferon-gamma release assay (IGRA) or tuberculin skin test (TST) result equal to or greater than 5 or $10 \mathrm{~mm}$, depending on whether or not they are immunosuppressed $^{26}$. These are the methods currently available, only allowing for an indirect interpretation of the presence of LTB, and entirely relying on a fully complete immune response by the host after it has been exposed to Mtb antigens. None of these methods makes it possible to distinguish between active infection and latent infection, cured or untreated $\mathrm{TB}$, nor to differentiate recent exposure from past exposure.

TST result can be influenced by past vaccination with BCG, leading to false-positive results. However, impact of BCG progressively reduces over time, is scant after 15 years, and a strongly positive TST result is very unlikely attributable to prior BCG vaccination. TST false positive results may be due to previous exposure to non-tuberculosis mycobacteria ${ }^{27}$. On the other hand, IGRAs have better sensitivity and specificity, but can be influenced by inflammatory activity, lymphopenia, or immunosuppressive therapies such as high-dose corticosteroids ${ }^{28}$. Multiple reports describe variation in IGRA results in patients who are evaluated on several occasions, with conversions and reversals of IGRA, and the clinical outcome of these phenomenon remains to be established ${ }^{29}$.

Prior to immunosuppression treatments, patients should be screened for TB. LTB treatment is considered not only according to test results, but also regarding individual risk of TB reactivation, ongoing use of immunosuppressive drugs, or predicted future need, as well as LTB treatment toxicity risk.

\section{CYTOMEGALOVIRUS}

CMV infection in immunosuppressed patients is often severe and can be fatal. A retrospective analysis of AAV patients found that, apart from previously described risk factors such as cyclophosphamide, rituximab, and corticosteroids, severe disease and granulomatosis with polyangiitis (GPA) were independent risk factors for CMV infection $^{30,31}$. CMV infection in the setting of AAIDs is a wide theme and prevention strategies are still being debated. Whenever CMV infection or risk factors for severe CMV disease are suspected, consultation with an infectious diseases expert should be sought.

\section{PULMONARY PNEUMOCYSTOSIS PROPHYLAXIS}

There are already guidelines recommending PCP prophylaxis for certain well-established oncology and transplantation settings ${ }^{32}$. However, PCP prophylaxis in patients with AllDs is still a gray area. Additional risk factors may exist and objective individual risk stratification is often difficult, since $\mathrm{CD} 4^{+}$lymphocyte count may not reflect PCP risk in the same way it does for HIV patients ${ }^{33}$. Nevertheless, it is beyond question that prevention in this setting saves lives, since PCP in non-HIV patients usually progresses with more rapid and severe symptoms, patients tend to experience worse outcomes, mortality rates range between $30-60 \%{ }^{34}$, and PCP diagnosis is frequently challenging ${ }^{35}$.

A 2007 systematic review by Green et al. proposed that prophylactic trimethoprim-sulfamethoxazole (TMP/SMX) should be considered when the risk of PCP is above $6.2 \%^{36}$. A 2014 review by Roux et al. provided some insight into PCP risk stratification, showing that in the setting of AAIDs with renal involvement, the most common underlying condition in PCP cases is GPA ( $8 \%-12 \%$ ), followed by polyarteritis nodosa (PAN) (6.5\%), and that SLE accounts for $2 \%^{37}$. In a recent systematic review, according to pooled data, PCP overall incidence in GPA is $6 \%$, and these patients account for $75 \%$ of PCP cases among AAVs ${ }^{38}$.

Impaired cellular immunity due to lymphopenia and drugs may also contribute to PCP risk. Although corticosteroids are the drugs most commonly implicated as a risk, there are still some conflicting data regarding the threshold daily dose, the cumulative dose, the administration route, the underlying AAID, and whether the type of combination regimens with other immunosuppressive drugs can also impact PCP risk. Prolonged neutropenia and recurrent or active CMV infection may also increase PCP risk ${ }^{39}$.

Published data regarding PCP risk and indications for prophylaxis are summarized in Table 1.

$\mathrm{TMP} / \mathrm{SMX}$ is the drug most frequently used in PCP prophylaxis, either 400/80 mg once a day or double-strength tablets 800/160 mg, given three times per week. When necessary, alternatives include atovaquone, aerosolized pentamidine, or dapsone ${ }^{33}$. 


\section{Table 1}

Situations where PCP prophylaxis is recommended $7,32,33,36,37,42$

In the setting of AAIDs, renal involvement, and need for immunosuppressive treatment

- Routine prophylaxis during induction therapy of GPA

- Routine prophylaxis during induction therapy of PAN

- GPA and treatment with prednisone $\geq 20 \mathrm{mg} / \mathrm{d}$ for $\geq 1$ month

- AAV treated with prednisone $\geq 20 \mathrm{mg} / \mathrm{d}$ for $\geq 1$ month plus cyclophosphamide or rituximab

- Connective tissue disease with renal involvement and treatment with prednisone $\geq 20 \mathrm{mg} / \mathrm{d}$ for $\geq 1$ month

- Patients receiving cyclophosphamide

- Patients receiving prednisone $\geq 20 \mathrm{mg} / \mathrm{d}$ for $\geq 1$ month plus a second immunosup pressive drug

- Patients receiving methotrexate and prednisone $\geq 20 \mathrm{mg} / \mathrm{d}$ for $\geq 1$ month Other settings

- Solid organ transplant recipients

- Selected autologous HCT recipients

- Allogeneic HCT recipients

- Patients with acute lymphocytic leukemia

- Patients receiving alemtuzumab

- Patients receiving idelalisib

- Patients receiving concomitant temozolomide and radiotherapy

- Patients receiving multiple chemotherapeutic agents

- Patients with polymyositis/dermatomyositis who have interstitial pulmonary fibrosis and high-dose corticosteroids treatment

- Prednisone $\geq 20 \mathrm{mg} / \mathrm{d}$ for $\geq 1$ month and another cause of immunocompromise AAV - Antineutrophil cytoplasmic antibody-associated vasculitis; GPA - granulomatosis with polyangiitis; HCT - hematopoietic cell transplant; PAN - polyarteritis nodosa

Chemoprophylaxis should be maintained as long as immunosuppressive treatments last and during increase in dose or number of immunosuppressive drugs. In patients treated with high-dose corticosteroids and/or cyclophosphamide, PCP risk may persist after treatment discontinuation.

Available data confirms that all TMP/SMX regimens appear to be safe and are recommended for PCP prophylaxis, particularly in patients with GPA or microscopic polyangiitis (MPA). It may also be considered in SLE patients on high corticosteroid therapy ${ }^{38}$, even though TMP/ SMX in SLE patients is not usually routinely recommended, due to the theoretical risk of TMP/SMX induced flare, along with the low incidence of PCP in these patients ${ }^{33,37}$.

In GPA patients, the role of TMP/SMX prophylaxis seems to be particularly beneficial. Not only is GPA the most common AlID associated with PCP, but TMP/SMX has also been used as induction treatment in GPA limited to upper and lower airways without systemic involvement $^{33}$. Data from renal transplant recipients suggest MMF may have some protective effect against $\mathrm{PCP} 40$.

TMP/SMX may also confer some protection against community-acquired respiratory, gastrointestinal, and urinary tract infections. It has been debated whether routine use of TMP/SMX in patients on immunosuppressants could also prevent salmonellosis, infection with Haemophilus species and staphylococci, and depending on dosing regimens, episodes of listeriosis, nocardiosis, and legionellosis, as well ${ }^{41}$.

\section{IMMUNIZATIONS}

Despite scarce data, there is awareness of the higher burden of vaccine-preventable diseases (VPD) in AlIDs, as confirmed by a 2019 systematic literature review ${ }^{43}$. These patients are prone to contracting influenza and influenza-related complications, pneumococcal disease, $\mathrm{HZ}$, as well as having a higher prevalence of genital human papilloma virus (HPV), including high-risk serotypes. The risk of pneumococcal disease, $\mathrm{HZ}$, and HPV was higher in SLE patients. These data stress the importance of preventing infection through immunization with individualized tailored strategies.

AlIDs do not seem to increase the risk for developing severe COVID-1944. However, vaccination is advised, since these patients tend to have more frequent comorbidities related to severe COVID-19 risk, such as advanced age, kidney and heart disease, pulmonary disease, hypertension, obesity, and diabetes.

Recommendations regarding vaccination are summarized in Table 2.

\section{HBV REACTIVATION RISK}

All patients must be screened for HBV infection prior to immunosuppression. HBV-R can lead to fulminant hepatic failure and high mortality rate.

Risk stratification is a useful tool, and takes into account HBV markers, underlying disease, type and duration of immunosuppressants. Table 3 shows risk stratification and strategies.

Irrespective of the pharmacologic category of immunosuppressant that is ongoing or is predicted to be used, patients with chronic HBV infection should receive antiviral therapy. Antivirals such as tenofovir (tenofovir disoproxil fumarate or tenofovir alafenamide) or entecavir should be used in patients warranting antiviral prophylaxis or treatment, since they have higher genetic barrier. Lamivudine is no longer recommended in these settings, since it has a lower genetic barrier and it is frequent for resistant viral variants to emerge after prolonged use, typically after 6 months ${ }^{48,49}$.

Once immunosuppressive therapy is stopped, antiviral treatment should be maintained for at least 6 months, or $12^{48}-18^{49}$ months in high-risk patients, particularly if a B-cell depleting agent such as rituximab was used. In such cases, monitoring is still warranted, since cases of late HBV-R have been described ${ }^{50}$.

Even though risk stratification is useful, in real life objective stratification may not be straightforward, transition between risk categories is frequent, and there are differences in HBV prophylaxis or pre-emptive therapy orientations regarding detectability of $\mathrm{HBsAg}$, anti-HBs and anti-HBC.

The American Association for the Study of Liver Disease (AASLD) recommends antiviral prophylaxis in $\mathrm{HBsAg}(-)$, anti- $\mathrm{HBC}(+)$ patients receiving anti-CD20 antibody therapy as rituximab, irrespective of anti-HBs titer ${ }^{48}$. The European Association for the Study of the Liver (EASL) also recommends such strategy, specifically regarding 


\section{Table 2}

Recommendations for vaccination in AllDs ladapted from Furer et al. ${ }^{45}$ and Soy M et al. $.46,47$ )

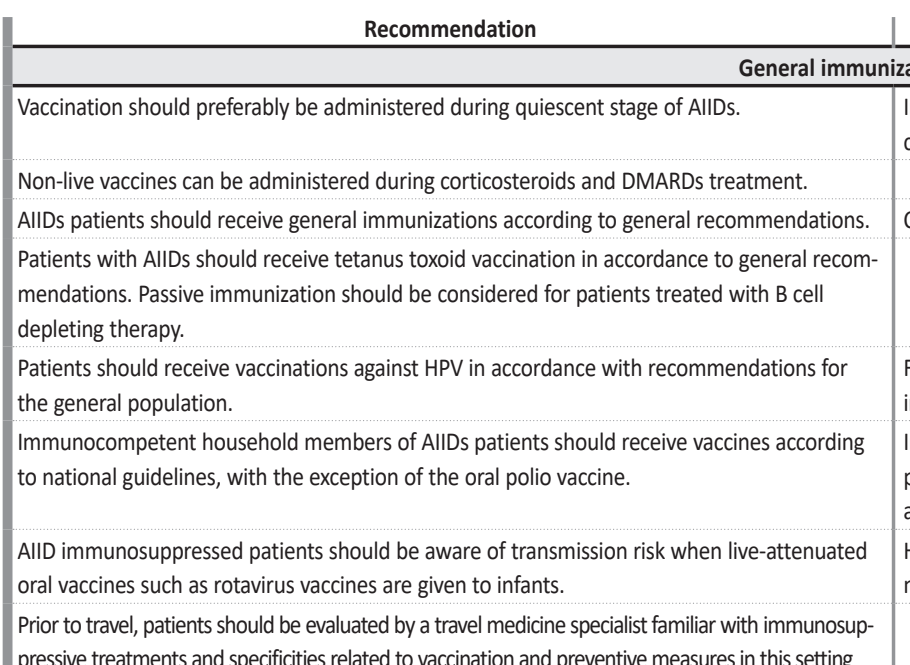

Comment

izations

In patients with active disease, immunization should not be precluded and should be considered on individual basis.

Caution: live-attenuated vaccines administration, see below.

Female patients with SLE are at a particular high risk of genital HPV infection, including high-risk serotypes.

Immunocompetent individuals, who live in a household with immunosuppressed patients, should receive inactivated vaccines as well as live-attenuated vaccines such as MMR, according to national guidelines.

Highly immunocompromised patients should avoid handling diapers of infants vaccinated against rotavirus for at least 4 weeks following the administration of the vaccine.

\section{Recommendations regarding specific immunosuppressive treatments}

Vaccines should be preferably administered prior to planned immunosuppression, in particu-

lar B cell depleting therapy.

In patients on B cell-depleting therapy, vaccination should be given at least 6 months after the administration and 4 weeks before the next course of treatment.

Necessary immunosuppressive treatment in severe cases should not be delayed and immunosuppressants should be prioritized over early administration of vaccines.

When this time window is not possible, vaccination may be considered under B-cell depleting therapy, taking into account potential suboptimal response to vaccine.

Pneumococcal vaccination should be strongly considered.

Annual influenza vaccination should be strongly considered.

Hepatitis A and/or B vaccine should be administered for non-immune patients at risk.

Herpes zoster vaccination may be considered in high-risk patients.

Live-attenuated vaccines should generally be avoided in patients on immunosuppressive treatment

When necessary, live-attenuated vaccines can be given 4 weeks before immunosuppressive treatment initiation. If immunosuppressants have already been given, vaccination should take place when $\geq 4$ weeks have passed since last administration.

Vaccination against yellow fever should be generally avoided in AlIDs patients

on immunosuppression

Immunization recommended for patients $\geq 50$ years old, using:

- a live-attenuated vaccine if administration is not contra-indicated or

- a new non-live recombinant subunit adjuvant zoster vaccine, when available.

Definition of immunosuppressive therapy:

- prednisone $\geq 20 \mathrm{mg} / \mathrm{d}$ or equivalent for $\geq 2$ weeks

- methotrexate $\geq 0.4 \mathrm{mg} / \mathrm{kg} /$ week

- azathioprine $\geq 3.0 \mathrm{mg} / \mathrm{kg} / \mathrm{day}$

- 6-mercaptopurine $\geq 1.5 \mathrm{mg} / \mathrm{kg} / \mathrm{day}$

- bDMARDs

- tsDMARDs

For patients traveling to endemic countries, withholding immunosuppressive therapy to allow a safe vaccination, or measuring serology in previously exposed patients may be considered.

COVID-19 vaccination

Vaccination should be preferably made when disease activity is under control and when there is no concurrent infection.

Vaccination of patients receiving high-dose corticosteroids should be done when the daily corticosteroids dose falls below prednisone $10 \mathrm{mg} /$ day or its equivalent.

In clinically stable patients, the scheduled dose of methotrexate before the vaccination and the subsequent weekly dose may be skipped.

For patients who are receiving intravenous cyclophosphamide, cyclophosphamide should be given approximately one week after each vaccine dose, when feasible.

Ideally, vaccination should be done before the initiation of any bDMARDs.

Patients receiving rituximab should be vaccinated at least 4 weeks before treatment or 6 months after treatment is received.

Patients who are more likely to have drug allergies such as SLE patients should be monitored for a longer period of time (up to $150 \mathrm{~min}$ ) after vaccination.

AlIDs - auto-immune inflammatory diseases; bDMARDs - biological disease-modifying antirheumatic drugs; DMARDs - disease-modifying antirheumatic drugs; MMR - measles, mumps, and rubella vaccines; tsDMARDs - targeted synthetic disease-modifying antirheumatic drugs; SLE- systemic lupus erythematosus
Ongoing immunosuppressive drugs should be carefully reviewed before vaccination.

Low-degree immunosuppression does not appear to decrease antibody responses to vaccines.

A safety margin of 14 days before and after vaccination may be considered in clinically stable patients. 


\section{Table 3}

HBV-R risk and strategies (adapted from Terraul et al. ${ }^{48}$ and Lampertico et al. ${ }^{49}$ )

\begin{tabular}{|c|c|c|c|}
\hline Risk (\%) & HBV markers & Drugs & Strategies \\
\hline $\begin{array}{l}\text { Very high risk } \\
(>20 \%)\end{array}$ & $\mathrm{HBsAg}(+)$ & Anti-CD20 & \multirow{3}{*}{$\begin{array}{l}\text { Preventive antiviral therapy: } \\
\text { - concurrently with immunosuppressive therapy } \\
\text { - before immunosuppressive therapy if high HBV DNA level and delay is possible } \\
\text { Consider pre-emptive therapy in moderate risk }\end{array}$} \\
\hline $\begin{array}{l}\text { High risk } \\
(11-20 \%)\end{array}$ & $\mathrm{HBsAg}(+)$ & Prednisone $\geq 20 \mathrm{mg} /$ day, $\geq 4$ weeks & \\
\hline $\begin{array}{l}\text { Moderate risk } \\
(1-10 \%)\end{array}$ & $\begin{array}{l}\operatorname{HBsAg}(+) \\
\operatorname{HBsAg}(-) \text {, anti-HBc(+) }\end{array}$ & $\begin{array}{l}\text { Cytotoxic chemotherapy without corticosteroids } \\
\text { Anti-TNF } \\
\text { Anti-CD20 }\end{array}$ & \\
\hline $\begin{array}{l}\text { Low risk } \\
(<1 \%)\end{array}$ & $\mathrm{HBsAg}(-)$, anti-HBc(+) & High-dose corticosteroids & Frequent monitoring with ALT, HBsAg and HBV DNA every 1-3 months \\
\hline Very low risk & $\mathrm{HBsAg}(-)$, anti-HBc(+) & $\begin{array}{l}\text { Cytotoxic chemotherapy without corticosteroids } \\
\text { Anti-TNF } \\
\text { Methotrexate } \\
\text { Azathioprine }\end{array}$ & If frequent monitoring is not possible, consider antiviral prophylaxis \\
\hline
\end{tabular}

onco-hematological patients or those undergoing $\mathrm{HCT}^{49}$. Current guidelines do not focus specifically on AlIDs patients requiring anti-CD20 drugs.

The role for anti-HBs in screening before immunosuppressive therapy is still under debate, since its presence may not prevent HBV reactivation ${ }^{48}$. Nonetheless, anti-HBs might be useful in further characterization of risk stratification, as suggested by some studies comparing HBV-R in hematological and non-hematological patients, proposing that since patients with non-hematological diseases or rituximab-free regimens have a lower risk of HBV-R, they may not require anti-HBV prophylaxis if HBV DNA is undetectable and there is positivity for anti-HBs ${ }^{51}$. Additionally, high anti-HBs titer ( $\geq 100 \mathrm{mIU} / \mathrm{mL}$ ) was associated with a lower risk of HBV-R in patients who did not receive antiviral prophylaxis, compared to patients who had low baseline anti-HBs ( $<100 \mathrm{mIU} / \mathrm{mL})$, in a cohort of CD20-positive B-cell lymphoma patients treated with rituximab-based chemotherapy ${ }^{52}$. Nishida et al. ${ }^{53}$ also found that the combination of anti-HBc and anti-HBs titers may be a reliable and useful predictor for managing HBV-R; however, since antibody titers change significantly during immunosuppressive treatments, the decrease in anti-HBs titers may be more important for predicting HBV reactivation.

\section{STRONGYLOIDIASIS}

Immunosuppressed patients are at risk for Strongyloides stercoralis infection. Since this helminth's life cycle can occur entirely in human hosts and autoinfection is possible through larvae skin penetration after being passed on by stool, infection can persist for decades within the same host ${ }^{54}$. A cross-sectional study in an endemic region found an overall prevalence of strongyloidiasis in SLE patients of $15.6 \%{ }^{55}$. In a retrospective Portuguese cohort study of 415 AlIDs patients screened for strongyloidiasis, $13 \%$ had positive serology 56 .

In the setting of immunosuppression, severe disseminated infection can occur, as well as fulminant hyperinfection. Coinfection with human T-lymphotropic virus type I (HTLV-1) is also an important risk factor for severe disease, since it is associated with impaired immune response against Strongyloides and higher rates of treatment failure ${ }^{57,58}$. Corticosteroids, cytotoxic drugs and hypogammaglobulinemia have been associated with a higher risk of strongyloidiasis, as well as solid organ transplantation. Prior to immunosuppressants, patients should be screened for Strongyloidiasis, preferably with serologic tests and when positive, offered preventive treatment. If immunosuppression cannot be delayed and epidemiologic exposure is relevant, preventive treatment with ivermectin should be given, pending test results ${ }^{59}$. The optimal treatment regimen is uncertain, and most authors recommend ivermectin $200 \mathrm{mcg} / \mathrm{kg}$ daily for 2 days, performed again after 2 weeks, which is the duration of one auto-infection cycle ${ }^{60}$. Strongyloidiasis has also been described in AAIDs in the setting of immune inflammatory reconstitution syndrome (IRIS).

\section{PROGRESSIVE MULTIFOCAL LEUKOENCEPHALOPATHY}

PML is caused by reactivation of the polyomavirus JC, causing a severe demyelinating disease that can affect gray and white matter of the central nervous system, occurring almost exclusively in immunosuppressed patients. Apart from HIV-infection, PML cases have also been reported in cancer patients, particularly those with hematological diseases treated with rituximab, leading in 2007 to package inclusion of a "black box warning" 61 .

PML has also been described in AAIDs and risk seems be mostly related to the use of immunosuppressants such as corticosteroids, cyclophosphamide and MMF, apart from rituximab. Risk stratification according to AlIDs and/or immunosuppressants is difficult, and available data derives from international registries, cohort retrospective analysis and small case reports.

The FDA Adverse Event Reporting System (FAERS) database included 58 and 3 confirmed cases of PML in autoimmune and GPA/microscopic polyangiitis (MPA) rituximab-treated patients, respectively; the approximate total incidence rate ranged from $1.39-1.87$ cases per 10,000 
rituximab-exposed patients, including cancer patients ${ }^{62}$. A 2017 review of rituximab-related PML confirmed cases in GPA/MPA patients found a very low reporting rate defined as $<1$ per 10,000 patients, noting that these patients frequently also receive immunosuppressant agents and high-dose corticosteroid therapies that may be additional risk factors for $\mathrm{PML}^{16}$.

In a 2012 review within the FAERS database, of 34 confirmed cases of PML among patients with AIIDs, 17 had a diagnosis of SLE, suggesting that SLE patients appeared to have susceptibility to the development of PML, compared to patients with other systemic immunosuppressive treatments ${ }^{16}$. This was not confirmed in a recent observational study ${ }^{64}$, where, among a cohort of 7455 adult SLE patients, PML was suspected in one patient and confirmed in only one other, developing in the setting of severe lymphopenia and one year after cyclophosphamide treatment. Cyclophosphamide and PML risk were also suggested back in 2012 by Molloy et al., whose study found confirmed PML cases in 5 MMF-treated SLE patients and 12 SLE non-MMF treated patients, all of whom had been treated with other immunosuppressive agents, including cyclophosphamide ${ }^{16}$. PML is also described in kidney transplant recipients treated with MMF, with a reported incidence of 14.4 cases per-100,000 person-years, although this was not statistically significant when compared with non-MMF treated patients ${ }^{65}$.

PML can also develop in the setting of immune reconstitution after withdrawal of immunosuppressive therapies, as suggested by the findings that some patients present inflammatory changes on MRI, hinting an "inflammatory PML", similarly to what is very well described in the setting of HIV infection and IRIS ${ }^{16}$.

\section{IMMUNE RECONSTITUTION INFLAMMATORY SYNDROME}

IRIS was first described in HIV patients after initiation of antiretroviral therapy. IRIS can present by paradoxically worsening symptoms of a previously documented infection despite ongoing treatment, or by unmasking of an until-then unknown, quiescent opportunistic disease. The advances in the treatment of AAIDs and cancer patients have allowed for IRIS cases to occur when immunosuppressive treatment is withdrawn or scaled down.

The mechanisms subjective to IRIS are still incompletely understood. Information compiled from HIV patients and animal models suggest that not only lymphopenia itself, but also failure to clear the pathogen by $T$ cells before $T$ cell reconstitution takes place can result in excessive priming of the innate immune system once immune recovery ensues, causing an exaggerated proinflammatory response to the opportunistic disease, due to a sudden shift from immunosuppression to immune reconstitution 66,67 .

IRIS symptoms depend on the underlying opportunistic pathogen and multiple cytokines and chemokines have been pointed out to be involved in the pathophysiology, such as interleukin (IL)-6, IL-12, TNF $\alpha$ and interferon- $\gamma^{66}$.

The incomplete characterization of IRIS in the setting of AAIDs makes it difficult to predict, diagnose, and treat.
The very few reports of IRIS in immunosuppressed AIID patients with renal involvement include cases such as an SLE patient with non-tuberculous mycobacteria infection after previous treatment with ciclosporin, azathioprine, MMF, and leflunomide ${ }^{68}$, and another SLE patient previously treated with high-dose corticosteroid, MMF, and tacrolimus who presented Strongyloides stercoralis, HTLV-1, and CMV coinfection $^{69}$.

A clinical trial with 180 GPA patients treated with cyclophosphamide and/or corticosteroids found that, in a group of patients who had HZ, most of them developed it after cyclophosphamide was discontinued, hinting at the possibility of underlying immune reconstitution ${ }^{70}$.

\section{CONCLUSION}

The higher infection risk observed in AAID patients and renal disease is related not only to the underlying disease, but also to the drugs most commonly used in this setting. Infection risk assessment is fundamental to define individualized tailored strategies for infection prevention, either by preventive treatment/prophylaxis or through vaccination. Close monitoring is warranted during periods of more intensive immunosuppression, but late reactivation of infection is possible and a small number of IRIS cases has emerged. Given the uncertainty in some infection prevention strategies in this setting, further risk-benefit studies are required.

Disclosure of potential conflicts of interest: none declared.

\section{References}

1. Glenn DA, Henderson CD, O'Shaughnessy M, et al. Infection-related acute care events among patients with glomerular disease [published correction appears in Clin J Am Soc Nephrol. 2021 Mar 8;16(3):456-457]. Clin J Am Soc Nephrol. 2020;15(12):1749-1761. doi:10.2215/ CJN.05900420

2. McGregor JG, Negrete-Lopez R, Poulton CJ, et al. Adverse events and infectious burden, microbes and temporal outline from immunosuppressive therapy in antineutrophil cytoplasmic antibody-associated vasculitis with native renal function. Nephrol Dial Transplant. 2015;30(1):i171-i181. doi:10.1093/ndt/gfv045

3. Sarica SH, Dhaun N, Sznajd J, et al. Characterizing infection in anti-neutrophil cytoplasmic antibody-associated vasculitis: results from a longitudinal, matched-cohort data linkage study. Rheumatology (Oxford). 2020;59(10):3014-3022. doi:10.1093/rheumatology/keaa070

4. Yin $P$, Li J, Wen $Q$, et al. Infection-related hospitalization after intensive immunosuppressive therapy among lupus nephritis and ANCA glomerulonephritis patients. Ren Fail. 2020;42(1):474-482. doi:10.1080/0886022X.2020.1763400

5. Pryor BD, Bologna SG, Kahl LE. Risk factors for serious infection during treatment with cyclophosphamide and high-dose corticosteroids for systemic lupus erythematosus [published correction appears in Arthritis Rheum 1997 Sep;40(9):1711]. Arthritis Rheum. 1996;39(9):1475-1482. doi:10.1002/art.1780390906

6. Malpica L, Moll S. Practical approach to monitoring and prevention of infectious complications associated with systemic corticosteroids, antimetabolites, cyclosporine, and cyclophosphamide in nonmalignant hematologic diseases. Hematology Am Soc Hematol Educ Program. 2020;2020(1):319-327. doi:10.1182/hematology.2020000116

7. Yates $M$, Watts RA, Bajema IM, et al. EULAR/ERA-EDTA recommendations for the management of ANCA-associated vasculitis [published correction appears in Ann Rheum Dis. 2017 Aug;76(8):1480]. Ann Rheum Dis. 2016;75(9):1583-1594. doi:10.1136/annrheumdis-2016-209133

8. Mélet J, Mulleman D, Goupille P, Ribourtout B, Watier H, Thibault G. Rituximab-induced T cell depletion in patients with rheumatoid arthritis: association with clinical response. Arthritis Rheum. 2013;65(11):2783-2790. doi:10.1002/art.38107

9. Fiocca Vernengo F, Beccaria CG, Araujo Furlan CL, et al. CD8+ T cell immunity is compromised by anti-CD20 treatment and rescued by interleukin-17A. mBio. 2020;11(3):e00447-20. Published 2020 May 12. doi:10.1128/mBio.00447-20

10. Christou EAA, Giardino G, Worth A, Ladomenou F. Risk factors predisposing to the development of hypogammaglobulinemia and infections post-Rituximab. Int Rev Immunol. 2017;36(6):352-359. doi:10.1080/08830185.2017.1346092

11. Kridin K, Ahmed AR. Post-rituximab immunoglobulin M (IgM) hypogammaglobulinemia. Autoimmun Rev. 2020;19(3):102466. doi:10.1016/j.autrev.2020.102466 
12. Wingfield T, Jani M, Krutikov $M$, et al. Cryptococcal meningitis in an HIV-negative patient with rheumatoid arthritis treated with rituximab. Rheumatology (Oxford). 2011;50(9):1725-1727. doi:10.1093/rheumatology/ker210

13. Sánchez-Ojanguren J, Isern-Segura I, Chico-Chumillas C, Javaloyas-de-Morlius M. Meningoencefalitis por Crytococcus neoformans en mujer tratada con rituximab [Cryptococcus neoformans meningoencephalitis in a patient treated with rituximab]. Med Clin (Barc). 2009;133(4):157-158. doi:10.1016/j.medcli.2008.09.036

14. Ngiu CS, Said MS, Periyasamy P, Low SF. Nocardiosis in a patient with rheumatoid arthritis treated with rituximab and a summary of reported cases. BMJ Case Rep. 2010;2010:bcr1120092421. Published 2010 Sep 29. doi:10.1136/bcr.11.2009.2421

15. Dentan C, Mazet R, Gilson M, Marchou-Lopez S, Gaudin P. Rheumatoid arthritis, alveolar echinococcosis, and rituximab: a case report. Joint Bone Spine. 2012;79(3):325-327. doi:10.1016/j. jbspin.2011.10.014

16. Molloy ES, Calabrese LH. Progressive multifocal leukoencephalopathy associated with immunosuppressive therapy in rheumatic diseases: evolving role of biologic therapies. Arthritis Rheum. 2012;64(9):3043-3051. doi:10.1002/art.34468

17. Zonozi $R$, Wallace $Z S$, Laliberte $K$, et al. Incidence, clinical features, and outcomes of late-onset neutropenia from rituximab for autoimmune disease. Arthritis Rheumatol. 2021;73(2):347-354 doi:10.1002/art.41501

18. Xiong A, Xiong $C$, Yang $G$, et al. The role of mycophenolate mofetil for the induction of remission in ANCA-associated vasculitis: a meta-analysis. Front Med (Lausanne). 2021;8:609924. Published 2021 Mar 1. doi:10.3389/fmed.2021.609924

19. Trotter JL, Rodey GE, Gebel HM. Azathioprine decreases suppressor T cells in patients with multiple sclerosis. N Engl J Med. 1982;306(6):365-366. doi:10.1056/NEJM198202113060614

20. Tiede I, Fritz G, Strand S, et al. CD28-dependent Rac1 activation is the molecular target of azathioprine in primary human CD4+ T lymphocytes. J Clin Invest. 2003;111(8):1133-1145. doi:10.1172/JCl16432

21. Espiritu Al, Pasco PMD. Efficacy and tolerability of azathioprine for neuromyelitis optica spectrum disorder: a systematic review and meta-analysis. Mult Scler Relat Disord. 2019;33:22-32. doi:10.1016/j.msard.2019.05.011

22. Fox GJ, Dobler CC, Marais BJ, Denholm JT. Preventive therapy for latent tuberculosis infection-the promise and the challenges. Int J Infect Dis. 2017;56:68-76. doi:10.1016/j.ijid.2016.11.006

23. Baddley JW, Cantini F, Goletti D, et al. ESCMID Study Group for Infections in Compromised Hosts (ESGICH) Consensus Document on the safety of targeted and biological therapies: an infectious diseases perspective (Soluble immune effector molecules [l]: anti-tumor necrosis factor- $\alpha$ agents) Clin Microbiol Infect. 2018;24 Suppl 2:S10-S20. doi:10.1016/j.cmi.2017.12.025

24. Wang J, Wang R, Wang H, et al. Glucocorticoids suppress antimicrobial autophagy and nitric oxide production and facilitate mycobacterial survival in macrophages. Sci Rep. 2017;7(1):982. Published 2017 Apr 20. doi:10.1038/s41598-017-01174-9

25. Machuca I, Vidal E, de la Torre-Cisneros J, Rivero-Román A. Tuberculosis in immunosuppressed patients. Tuberculosis en pacientes inmunodeprimidos. Enferm Infecc Microbiol Clin (Engl Ed). 2018:36(6):366-374. doi:10.1016/j.eimc.2017.10.009

26. Duarte R, Campainha S, Cotter J, et al. Position paper on tuberculosis screening in patients with immune mediated inflammatory diseases candidates for biological therapy. Acta Reumatol Port. 2012:37(3):253-259.

27. Wang L, Turner MO, Elwood RK, Schulzer M, FitzGerald JM. A meta-analysis of the effect of Bacille Calmette Guérin vaccination on tuberculin skin test measurements [published correction appears in Thorax. 2003 Feb;58(2):188.]. Thorax. 2002;57(9):804-809. doi:10.1136/thorax.57.9.804

28. González-Moreno J, García-Gasalla M, Losada-López I, et al. IGRA testing in patients with immune-mediated inflammatory diseases: which factors influence the results?. Rheumatol Int. 2018;38(2):267-273. doi:10.1007/s00296-017-3852-9

29. Hatzara C, Hadziyannis E, Kandili A, et al. Frequent conversion of tuberculosis screening tests during anti-tumour necrosis factor therapy in patients with rheumatic diseases. Ann Rheum Dis, 2015;74(10):1848-1853. doi:10.1136/annrheumdis-2014-205376

30. Lim CC, Mok IYJ, Choo JCJ. Letter to the Editor: Time for cost-effectiveness studies for preventive strategies applied according to risk of cytomegalovirus-related morbidity and mortality in ANCA-associated vasculitis. Clin Rheumatol. 2018;37(7):2011-2012. doi:10.1007/s10067-018-4101-7

31. Morishita M, Sada KE, Matsumoto Y, et al. Risk factors for cytomegalovirus infection in patients with antineutrophil cytoplasmic antibody-associated vasculitis. PLoS One. 2019;14(7):e0218705. Published 2019 Jul 10. doi:10.1371/journal.pone.0218705

32. Maertens J, Cesaro S, Maschmeyer G, et al. ECIL guidelines for preventing Pneumocystis jirovecil pneumonia in patients with haematological malignancies and stem cell transplant recipients. Antimicrob Chemother. 2016;71(9):2397-2404. doi:10.1093/jac/dkw157

33. Ghembaza A, Vautier M, Cacoub P, Pourcher V, Saadoun D. Risk factors and prevention of pneumocystis jirovecii pneumonia in patients with autoimmune and inflammatory diseases. Chest. 2020;158(6):2323-2332. doi:10.1016/j.chest.2020.05.558

34. Pereda CA, Nishishinya-Aquino MB, Brito-García N, Díaz Del Campo Fontecha P, Rua-Figueroa I. Is cotrimoxazole prophylaxis against Pneumocystis jirovecii pneumonia needed in patients with systemic autoimmune rheumatic diseases requiring immunosuppressive therapies? [published online ahead of print, 2021 Mar 3]. Rheumatol Int. 2021;10.1007/s00296-021-04808-4. doi:10.1007/s00296-021-04808-4

35. Su YS, Lu JJ, Perng CL, Chang FY. Pneumocystis jirovecii pneumonia in patients with and without human immunodeficiency virus infection. I Microbiol Immunol Infect. 2008:41(6):478-482.

36. Green H, Paul M, Vidal L, Leibovici L. Prophylaxis of Pneumocystis pneumonia in immunocompromised non-HIV-infected patients: systematic review and meta-analysis of randomized controlled trials. Mayo Clin Proc. 2007:82(9):1052-1059 doi:10.4065/82.9.1052

37. Roux A, Gonzalez F, Roux M, et al. Update on pulmonary Pneumocystis jirovecii infection in non-HIV patients. Med Mal Infect. 2014;44(5):185-198. doi:10.1016/j.medmal.2014.01.007

38. Pereda CA, Nishishinya-Aquino MB, Brito-García N, Díaz Del Campo Fontecha P, Rua-Figueroa I. Is cotrimoxazole prophylaxis against Pneumocystis jirovecii pneumonia needed in patients with systemic autoimmune rheumatic diseases requiring immunosuppressive therapies? [published online ahead of print, 2021 Mar 3]. Rheumatol Int. 2021;10.1007/s00296-021-04808-4. doi:10.1007/s00296-021-04808-4

39. Fishman JA. Pneumocystis jiroveci. Semin Respir Crit Care Med. 2020;41(1):141-157. doi:10.1055/ s-0039-3399559

40. Husain S, Singh N. The impact of novel immunosuppressive agents on infections in organ transplant recipients and the interactions of these agents with antimicrobials. Clin Infect Dis. 2002;35(1):5361. doi:10.1086/340867

41. Bodro M, Paterson DL. Has the time come for routine trimethoprim-sulfamethoxazole prophylaxis in patients taking biologic therapies?. Clin Infect Dis. 2013;56(11):1621-1628. doi:10.1093/ $\mathrm{cid} / \mathrm{cit} 07$

42. Fishman JA, Gans H; AST Infectious Diseases Community of Practice. Pneumocystis jiroveci in solid organ transplantation: Guidelines from the American Society of Transplantation Infectious Diseases Community of Practice. Clin Transplant. 2019;33(9):e13587. doi:10.1111/ctr.13587

43. Furer $\mathrm{V}$, Rondaan $\mathrm{C}$, Heijstek $\mathrm{M}$, et al. Incidence and prevalence of vaccine preventable infections in adult patients with autoimmune inflammatory rheumatic diseases (AlIRD): a systemic literature review informing the 2019 update of the EULAR recommendations for vaccination in adult patients with AllRD RMD Open. 2019:5(2):e01041. Published 2019 Sep 19. doi:10.1136/rmdopen-2019-001041

44. Gianfrancesco M, Hyrich KL, Al-Adely S, et al. Characteristics associated with hospitalisation for COVID-19 in people with rheumatic disease: data from the COVID-19 Global Rheumatology Alliance physician-reported registry. Ann Rheum Dis. 2020;79(7):859-866. doi:10.1136/annrheumdis-2020-217871

45. Furer V, Rondaan C, Heijstek MW, et al. 2019 update of EULAR recommendations for vaccination in adult patients with autoimmune inflammatory rheumatic diseases. Ann Rheum Dis. 2020;79(1):39-52. doi:10.1136/annrheumdis-2019-215882

46. Soy M, Keser G, Atagunduz P, et al. A practical approach for vaccinations including COVID-19 in autoimmune/autoinflammatory rheumatic diseases: a non-systematic review [published online ahead of print, 2021 Mar 22]. Clin Rheumatol. 2021;1-13. doi:10.1007/s10067-021-05700-z

47. Arnold J, Winthrop K, Emery P. COVID-19 vaccination and antirheumatic therapy [published online ahead of print, 2021 Mar 12]. Rheumatology (Oxford). 2021;keab223. doi:10.1093/rheumatology/ keab223

48. Terrault NA, Lok ASF, McMahon BJ, et al. Update on Prevention, Diagnosis, and Treatment of Chronic Hepatitis B: AASLD 2018 Hepatitis B Guidance. Clin Liver Dis (Hoboken). 2018;12(1):33-34. Published 2018 Aug 22. doi:10.1002/cld.728

49. European Association for the Study of the Liver. EASL 2017 Clinical Practice Guidelines on the management of hepatitis B virus infection. J Hepatol. 2017;67(2):370-398. doi:10.1016/j. jhep.2017.03.021

50. Nakaya A, Fujita S, Satake A, et al. Delayed HBV reactivation in rituximab-containing chemotherapy: How long should we continue anti-virus prophylaxis or monitoring HBV-DNA? Leuk Res. 2016;50:46-49. doi:10.1016/j.leukres.2016.09.014

51. Cholongitas E, Haidich AB, Apostolidou-Kiouti F, Chalevas P, Papatheodoridis GV. Hepatitis B virus reactivation in HBsAg-negative, anti-HBc-positive patients receiving immunosuppressive therapy: a systematic review. Ann Gastroenterol. 2018;31(4):480-490. doi:10.20524/aog.2018.0266

52. Cho Y, Yu SJ, Cho EJ, et al. High titers of anti-HBs prevent rituximab-related viral reactivation in resolved hepatitis B patient with non-Hodgkin's lymphoma. J Med Virol. 2016;88(6):1010-1017. doi:10.1002/jmv.24423

53. Nishida T, Matsubara T, Yakushijin T, Inada M. Prediction and clinical implications of HBV reactivation in lymphoma patients with resolved $\mathrm{HBV}$ infection: focus on anti-HBs and anti- $\mathrm{HBC}$ antibody titers. Hepatol Int. 2019;13(4):407-415. doi:10.1007/s12072-019-09966-z

54. Morais JA. Occurrence of native Strongyloidiasis in Portugal. Retrospective revision. Rev Port D Inf. 2012;8(2):85-93.

55. Juthong $\mathrm{S}$, Geater AF, Dekumyoy $\mathrm{P}$, et al. Prevalence and risk factors of strongyloidiasis in patients with systemic lupus erythematosus in Southern Thailand. Lupus. 2020;29(6):539-546. doi:10.1177/0961203320911091

56. Betkova S, Póvoas D, Simões $P$ et al. Strongyloides stercoralis screening results in an Infection risk assessment consultation. Oral presentation, 12th Congress on Infectious Diseases Update. Lisbon, January 2020

57. Carvalho EM, Da Fonseca Porto A. Epidemiological and clinical interaction between HTLV-1 and Strongyloides stercoralis. Parasite Immunol. 2004;26(11-12):487-497. doi:10.1111/j.0141 $-9838.2004 .00726 . x$

58. Terashima A, Alvarez H, Tello R, Infante R, Freedman DO, Gotuzzo E. Treatment failure in intestinal strongyloidiasis: an indicator of HTLV-I infection. Int J Infect Dis. 2002;6(1):28-30. doi:10.1016/ s1201-9712(02)90132-3

59. Stauffer WM, Alpern JD, Walker PF. COVID-19 and Dexamethasone: A Potential Strategy to Avoid Steroid-Related Strongyloides Hyperinfection. JAMA. 2020;324(7):623-624. doi:10.1001/ jama.2020.13170

60. $\mathrm{C}$ enter for International Blood and Marrow Transplant Research (CIBMTR); National Marrow Donor Program (NMDP); European Blood and Marrow Transplant Group (EBMT); Guidelines for preventing infectious complications among hematopoietic cell transplant recipients: a global perspective. Bone Marrow Transplant. 2009;44(8):453-558.

61. Rituxan warning. FDA Consum. 2007;41(2):3

62. Focosi D, Tuccori M, Maggi F. Progressive multifocal leukoencephalopathy and anti-CD20 monoclonal antibodies: What do we know after 20 years of rituximab. Rev Med Virol. 2019;29(6):e2077. doi:10.1002/rmv.2077

63. Berger JR, Malik V, Lacey S, Brunetta P, Lehane PB. Correction to: Progressive multifocal leukoencephalopathy in rituximab-treated rheumatic diseases: a rare event. J Neurovirol. 2018;24(3):332. doi:10.1007/s13365-018-0637-1

64. Kapoor T, Mahadeshwar P, Hui-Yuen J, et al. Prevalence of progressive multifocal leukoencephalopathy (PML) in adults and children with systemic lupus erythematosus. Lupus Sci Med. 2020;7(1):e000388. doi:10.1136/lupus-2020-000388 
65. Neff RT, Hurst FP, Falta EM, et al. Progressive multifocal leukoencephalopathy and use of mycophenolate mofetil after kidney transplantation. Transplantation 2008; 86:1474.

66. Aggarwal N, Barclay W, Shinohara ML. Understanding mechanisms underlying the pathology of immune reconstitution inflammatory syndrome (IRIS) by using animal models. Curr Clin Microbiol Rep. 2018;5(3):201-209. doi:10.1007/s40588-018-0099-5

67. Gupta M, Jafri K, Sharim R, et al. Immune reconstitution inflammatory syndrome associated with biologic therapy. Curr Allergy Asthma Rep. 2015;15(2):499. doi:10.1007/s11882-014-0499-4

68. Daum S, Moos V, Loddenkemper $C$, et al. Immunrekonstitutionssyndrom des Dünndarms be einer immunsupprimierten Patientin mit systemischem Lupus erythematodes und nichttuberkulöser Mykobakteriose [Immune reconstitution inflammatory syndrome (IRIS) of the small bowel in an immunocompromised patient suffering from systemic lupus erythematosus and non-tuberculous mycobacteriosis]. Z Rheumatol. 2008;67(4):277-283. doi:10.1007/s00393-008$-0298-1$

69. Ashida C, Kinoshita K, Nozaki Y, Funauchi M. Fatal outcome in a patient under immunosuppressant therapy infected with human T-lymphotropic virus type 1 (HTLV-1), cytomegalovirus (CMV) and Strongyloides stercoralis: a case report. BMC Infect Dis. 2020;20(1):470. Published 2020 Jul 2. doi:10.1186/s12879-020-05195-0

70. Wung PK, Holbrook JT, Hoffman GS, et al. Herpes zoster in immunocompromised patients: incidence, timing, and risk factors. Am J Med. 2005;118(12):1416. doi:10.1016/j.amjmed.2005.06.012

\section{ORCID}

Diana Póvoas (iD) 0000-0003-4531-2123

\section{Correspondence to:}

Diana Póvoas

Infectious Diseases Unit, Hospital de Curry Cabral, Centro Hospitalar Universitário Lisboa Central, EPE

E-mail: diana.silva@chlc.min-saude.pt 